\title{
MUSCULOSKELETAL DISORDERS AND PERCEPTION OF WORKING CONDITIONS: A SURVEY OF BRAZILIAN DENTISTS IN SÃO PAULO
}

\section{ARTÊNIO JOSÉ ÍSPER GARBIN ${ }^{1}$, GABRIELLA BARRETO SOARES ${ }^{1}$, RENATO MOREIRA ARCIERI', CLÉA ADAS SALIBA GARBIN ${ }^{1}$, and CARLOS EDUARDO SIQUEIRA ${ }^{2}$}

\author{
${ }^{1}$ São Paulo State University, Araçatuba, São Paulo, Brazil \\ Araçatuba Dental School, Social and Preventive Dentistry Program \\ ${ }^{2}$ University of Massachusetts Boston, Boston, Massachusetts, USA \\ College of Public and Community Service
}

\begin{abstract}
Objectives: To investigate the prevalence of work-related musculoskeletal disorders amongst dentists who work in public clinics in São Paulo, Brazil, to investigate their awareness of the presence of risk factors in the workplace, disability due to pain, and the influence of pain on this awareness and disability. Material and Methods: A cross-sectional study was conducted among 204 dentists who work in public health clinics in the northwest of São Paulo, Brazil. The data was collected through interviews, using the Nordic Questionnaire and the Work-Related Activities that May Contribute to Job-Related Pain Questionnaire. In the case of workers who reported pain, the Pain Disability Questionnaire (PDQ) and the Numeric Pain Scale were also administered. Statistical analyses were performed using SPSS 21.0. Results: Most dentists (81.4\%) had musculoskeletal disorders, especially in the neck, shoulders and lower back. We found that the presence of symptoms in the neck $(15.7 \%)$, shoulders (12.7\%) and lower back (15.7\%) were the major causes of absenteeism over the past 12 months. Occupational risk factors perceived as the most problematic ones were: bending or twisting the back in an awkward way, continuing to work when injured or hurt and working in the same position for long periods. Comparison between the symptomatic and asymptomatic dentists showed a statistically significant difference $(\mathrm{p}<0.05)$ in the perception of occupational risk factors. The analysis of the intensity of pain and disability with PDQ in the symptomatic dentists showed an average pain intensity of 3.8. Mean scores of the PDQ total (11.46) and its dimensions - functional condition (7.1) and psychosocial condition (4.4) - suggest a moderate disability in the dental surgeons. There was a strong t correlation $(\mathrm{r}=0.697)$ between pain intensity and the total score of disability caused by pain. Conclusions: Pain and work-related musculoskeletal disorders interfere significantly with the dentists' lives. In the case of dental surgeons there is a significant correlation between pain intensity and disability. Int J Occup Med Environ Health 2017;30(3):367-377
\end{abstract}

Key words:

Disability, Occupational health, Dentists, Musculoskeletal disorders, Risk factors, Cumulative trauma disorders

Funding: the study was supported by the São Paulo Research Foundation (FAPESP) (project No. 12/10187-8 "Occupational pain and musculoskeletal disorders: the dentist's future"). Project manager: Prof. Artênio José Ísper Garbin, Ph.D.

Received: June 29, 2015. Accepted: December 14, 2015.

Corresponding author: G. Barreto Soares, São Paulo State University, Araçatuba Dental School, Social and Preventive Dentistry Program, 1193 Jose Bonifácio St., Araçatuba, São Paulo, Brazil (e-mail: gabriella.barreto@yahoo.com.br). 


\section{INTRODUCTION}

Work-related musculoskeletal disorders (WMSDs) have serious socioeconomic implications in modern societies and are common among health professionals due to their exposure to various occupational hazards, such as: inadequate postures, handling of contaminated materials and increased levels of stress in the workplace [1]. These disorders are responsible for morbidity among many workers and are known as an important occupational problem due to their impact on remuneration, increased health costs, lowered productivity and a decreased quality of life [2].

Dentists present high prevalence of work-related musculoskeletal disorders, especially in the lower back region, neck and shoulders [3-5]. All over the world, mouth diseases have high prevalence and as a consequence a large number of patients seek dental treatment, which simultaneously increases the workload of dentists. Beyond that, the use of vibrating tools, excessive repetition of movements and maintaining inadequate postures for long periods are important risk factors that have been observed in the profession of a dentist [6].

Risk factors for the development of work-related musculoskeletal disorders in dental professionals are multifactorial, including: static or inadequate postures (particularly related to the neck and shoulders), repetitive movements and the use of force (most commonly related to the hand), lack of proper lighting (both in intensity and location), inadequate positioning of a patient, individual characteristics (physical conditioning, height, weight, general health status, gender, age) and psychosocial aspects [7,8].

Health professionals' awareness of the presence of risk factors in the workplace is of great importance, since it allows for the analysis of psychosocial factors that are related to a functional career, workload and work rhythm, social environment and interpersonal relationships. Exposure to these factors has greatly contributed to the presence of occupational diseases in dental practice and, beyond reducing productivity, has led dentists to early retirement or even to abandoning the profession [3,9]. Work-related musculoskeletal disorders have become the main cause of disabilities for workers - they have a substantial influence on their health and quality of life and represent an enormous challenge for health systems and social assistance programs throughout the world [4].

Disabilities induced by work-related musculoskeletal disorders are related to a decrease in mobility and function in all age ranges, interfere with the activities of daily life and make house tasks more difficult. Inability to work is a problem that leads to losses in personal and familial income, thus, creating psychological problems and social consequences for workers [10]. Nevertheless, no studies that would analyze pain disabilities among dentists and awareness of the presence of risk factors for work-related musculoskeletal disorders have been performed in Brazil. For these reasons, the goal of this study has been to investigate the prevalence of work-related musculoskeletal disorders among dentists who work in public clinics in São Paulo, Brazil, to investigate awareness of the presence of risk factors in the workplace, disability due to pain, and the influence of pain on this awareness and disability.

\section{MATERIAL AND METHODS}

This was an exploratory transversal study, which was performed in dental clinics of the Brazilian Public Health System that offer dental treatment in the northeastern health region of the state of São Paulo, Brazil. The dentists are hired to work $20 \mathrm{~h}$ per week or $40 \mathrm{~h}$ per week, during 5 days to treat on average 8-10 patients per day. The treatment includes: restorative, pediatric, oral surgery, endodontics, periodontics and prosthodontics procedures. In general each dentist works with a dental assistant.

The sample was composed of 204 dentists who were active in the municipalities. Dentists with physical disabilities, either congenital or acquired, that included upper and lower limbs, articulate or spinal, and those who were pregnant or lactating were excluded from the study sample. 


\section{Data collection}

Data collection was carried out during 4 months in 2014, after completion of a pilot study with 20 professionals, which was conducted to test the viability of the data collection tools.

The data variables related to sociodemographic characteristics, work and health of the dentists were acquired through a structured questionnaire designed specifically for this study. Sociodemographic variables included: age, gender and civil status. Work-related variables included: place of employment, number of hours worked, breaks between consults and time since graduation. Health-related variables included: body mass index (BMI), practice of physical exercises, consumption of cigarettes and alcohol, diagnosis of any disease in the last 12 months and the use of pain medications.

To evaluate the work-related musculoskeletal disorders, the Nordic questionnaire developed by Kuorinka et al. [11] was used, with the goal of standardizing measuring of the musculoskeletal symptoms. Brazilian version of the Nordic questionnaire was validated and adapted by Barros and Alexandre [12]. This tool consists of a posterior view of a human figure, which is subdivided in 9 anatomical regions: neck, shoulders, upper and lower back, elbows, wrists/hands, hips/thighs, knees and ankles/feet, and questions about the presence of musculoskeletal pain in any of the 9 anatomical areas, inability to perform normal activities and necessity to consult a health professional. The respondent has to signal with an $\mathrm{X}$ an affirmative or negative response (yes or no). A 12-month period prior to the time of the study was considered for the occurrence of musculoskeletal symptoms.

The questionnaire on risk factors at work that may contribute to musculoskeletal disorders (work-related) was also applied to identify how much work activities contribute to the development of musculoskeletal symptoms. This tool was originally developed in the United States by Rosecrance et al. [13].
In 2009 it was adapted and validated for Brazilian culture by Coluci and Alexandre [14]. This instrument comprises 15 items that evaluate individuals' awareness of job environment factors and their potential contribution to musculoskeletal disorders. The individuals were asked to indicate on a scale from 0 to 10 (with $0=$ nothing, and $10=\mathrm{alot}$ ) how much each variable contributed to the development of pain and lesions related to their current work tasks. Responses were classified in a scale of 3 categories, which indicated severity of symptoms in crescent order: the first, from $0-1$, indicated absence of symptoms; the second, from 2-7, indicated minimal to moderate symptoms; and the last, from 8-10, indicated severe symptoms.

To evaluate pain disabilities among the dentists who reported feeling pain in the past 12 months in some part of their body ( $\mathrm{N}=166,81.4 \%)$, the Pain Disability Questionnaire (PDQ) was used. It had been developed in 2003 by Anagnostis et al. [15], and the Brazilian version of the tool had been validated by Giordano and Alexandre [16].

The tool is composed of a total of 15 items that evaluate the effect of pain on: work, personal care, mobility, ability to stay sitting or still, lifting objects, walking or running, selfmedicate, medical consultations, social life, leisure, help in performing tasks and emotional state. These questions are divided into 2 categories: one category measures functional condition, and is composed of 9 items $(1-7,12,13)$, and the other measures psychosocial component, and is composed of 6 items $(8-11,14,15)$. The category corresponding to the functional condition may vary from 0 to 90 , and the psychosocial component category may vary from 0 to 60 points. For the total PDQ analysis, the scoring of the tool may vary from 0 to 150 and uses the following classification: a 0 score signifies no disability, scores 1-70 indicate a moderate disability, scores 71-100 demonstrate a severe disability and scores of 101-150 indicate an extreme disability.

Finally, the Numeric Pain Scale of 0 to 10 was used for evaluating the intensity of pain. Zero signifies absence of pain, and 10 is the worst pain imaginable [17]. 


\section{Data analysis}

Descriptive analyses by means of measures of central tendencies (simple frequencies, averages, and medians) and of dispersion (standard deviation - SD) were performed for categorization of: sociodemographics, occupational and population health, and musculoskeletal disorders; for the awareness of the presence of risk-factors at work, disability due to pain, and intensity of pain, respectively. The t-test was used for comparing women and men with the variables. The dentists were divided according to the presence or absence of musculoskeletal symptoms in the last 12 months in any body area. The non-parametric Mann-Whitney test was applied to compare awareness of the presence of risk factors between the individuals with and without symptoms. For the symptomatic subjects, the Spearman correlation coefficient was used for evaluating the relationship between disability and intensity of pain. All statistical analyses were conducted using the SPSS software, version 21.0.

\section{Ethical aspects}

The study was approved by the Committee on Ethics for Research on Human Beings of the College of Odontology of Araçatuba of the Paulista State University, and performed with the understanding and a written consent of every participant.

\section{RESULTS}

More than a half of the dentists were women (63.2\%), with average age of 43 years old $(\mathrm{SD}=9.5)$. The majority had practiced for an average of 21 years $(\mathrm{SD}=9.48)$. A large part of the sample worked in public and private services $(63.7 \%)$, with a workload of more than $8 \mathrm{~h}$ per day $(41.4 \%)$, and $38.4 \%$ reported not taking breaks between appointments. Most of the dentists worked in a restorative dentistry area (Table 1 ).

The table 2 shows that majority of the study subjects had normal BMI (53\%); however, there is a considerable part that
Table 1. Sociodemographic and occupational characteristics of the dentists, São Paulo, Brazil, 2014*

\begin{tabular}{|c|c|c|}
\hline \multirow[t]{2}{*}{ Variable } & \multicolumn{2}{|c|}{$\begin{array}{l}\text { Respondents } \\
(\mathrm{N}=204)\end{array}$} \\
\hline & $\mathrm{n}$ & $\%$ \\
\hline \multicolumn{3}{|l|}{ Gender } \\
\hline female & 129 & 63.2 \\
\hline male & 75 & 36.8 \\
\hline \multicolumn{3}{|l|}{ Age } \\
\hline $23-29$ years & 17 & 8.5 \\
\hline $30-39$ years & 47 & 23.6 \\
\hline 40-49 years & 78 & 39.2 \\
\hline 50-68 years & 57 & 28.6 \\
\hline \multicolumn{3}{|l|}{ Marital status } \\
\hline married/stable relationship & 146 & 71.9 \\
\hline single & 57 & 28.1 \\
\hline \multicolumn{3}{|l|}{ Clinic } \\
\hline public & 74 & 36.3 \\
\hline public and private & 130 & 63.7 \\
\hline \multicolumn{3}{|l|}{ Work time } \\
\hline 4 h/day & 18 & 8.9 \\
\hline $6 \mathrm{~h} /$ day & 26 & 12.8 \\
\hline $8 \mathrm{~h} /$ day & 75 & 36.9 \\
\hline$>8 \mathrm{~h} /$ day & 84 & 41.4 \\
\hline \multicolumn{3}{|l|}{ Dentistry area } \\
\hline restorative dentistry & 56 & 27.5 \\
\hline pediatric dentistry & 36 & 17.6 \\
\hline oral surgery & 24 & 11.8 \\
\hline general practice & 23 & 11.3 \\
\hline endodontics & 22 & 10.8 \\
\hline orthodontics & 17 & 8.3 \\
\hline prosthodontics & 11 & 5.4 \\
\hline periodontics & 8 & 3.9 \\
\hline dental implants & 7 & 3.4 \\
\hline \multicolumn{3}{|l|}{ Breaks } \\
\hline none & 65 & 38.4 \\
\hline $1-2$ & 79 & 45.9 \\
\hline$\geq 3$ & 27 & 15.7 \\
\hline
\end{tabular}

* Some strata do not sum up to initial total value because of missing data. 
Table 2. Health characteristics of the dentists, São Paulo, Brazil, 2014*

\begin{tabular}{|c|c|c|}
\hline \multirow{2}{*}{ Variable } & \multicolumn{2}{|c|}{$\begin{array}{l}\text { Respondents } \\
(\mathrm{N}=204)\end{array}$} \\
\hline & $\mathrm{n}$ & $\%$ \\
\hline \multicolumn{3}{|l|}{ Body mass index (BMI) } \\
\hline underweight $(<19)$ & 2 & 1.0 \\
\hline normal weight (19-25) & 105 & 51.5 \\
\hline overweight (26-30) & 71 & 34.5 \\
\hline obesity (> 30) & 20 & 9.8 \\
\hline \multicolumn{3}{|l|}{ Physical activity } \\
\hline yes & 136 & 66.7 \\
\hline no & 68 & 33.3 \\
\hline \multicolumn{3}{|l|}{ Kind of physical activity } \\
\hline resistance & 28 & 20.7 \\
\hline aerobic & 61 & 45.2 \\
\hline both & 46 & 34.1 \\
\hline \multicolumn{3}{|l|}{ Time after physical activity } \\
\hline$\leq 1$ year & 34 & 24.3 \\
\hline$>1$ year & 77 & 56.6 \\
\hline \multicolumn{3}{|l|}{ Frequency of physical acivity } \\
\hline 1-2/week & 47 & 34.6 \\
\hline$\geq 3 /$ week & 89 & 65.4 \\
\hline \multicolumn{3}{|l|}{$\begin{array}{l}\text { Health problems diagnosed } \\
\text { last year }\end{array}$} \\
\hline yes & 53 & 26.0 \\
\hline no & 151 & 74.0 \\
\hline \multicolumn{3}{|l|}{ Health problems } \\
\hline $\begin{array}{l}\text { work-related musculoskeletal } \\
\text { disorders (WMSD) }\end{array}$ & 33 & 62.3 \\
\hline others & 20 & 37.7 \\
\hline \multicolumn{3}{|l|}{ Pain medicine taken } \\
\hline yes & 122 & 60.1 \\
\hline no & 81 & 39.9 \\
\hline \multicolumn{3}{|l|}{ Medicine taken } \\
\hline analgesic & 27 & 22.1 \\
\hline anti-inflammatory & 40 & 32.7 \\
\hline combination & 37 & 30.3 \\
\hline others & 18 & 14.9 \\
\hline
\end{tabular}

was overweight/obese (44.3\%). A large number of the dentists (66.7\%) had practiced physical activity for $>1$ year $(69.4 \%)$. Twenty-six percent of those interviewed had had some health problems diagnosed in the last year, and $62.3 \%$ of those problems were related to musculoskeletal disorders. The majority of those interviewed $(60.1 \%)$ made use of pain medications. The table 3 indicates that $81.4 \%$ of the sample reported pain in the last 12 months. More than a half of the dentists reported neck pain (55.4\%), shoulders (52\%), and upper spine pain (50.5\%). Musculoskeletal pain in the lower regions (hips, thighs, knees, ankles, and feet) was observed in $<30 \%$ of the study subjects.

With regard to the inability to perform regular activities, $40.2 \%$ of the dentists reported that pain had interfered with the realization of their activities in the last 12 months. A little over a half $(50.5 \%)$ of the dentists due to musculoskeletal disorders had sought treatment by a health professional, and $41.7 \%$ of the participants reported pain in some part of their body in the last 7 days.

Neck and shoulder pain in the past 12 months was significantly higher among the female dentists than it was among the men $(p<0.001)$. It is worth to mention that women worked in both public and private services and had normal weight in BMI when compared to men.

The majority of those interviewed reported minimal/moderate problems $(80.7 \%)$ and there was a statistically significant association $(\mathrm{p}=0.018)$ between the problems related to the risk factors and the presence of pain (Table 4). In the comparison between the 2 groups, i.e., with pain $(81.4 \%)$ and without pain (18.6\%), one can see that the averages of the group with pain were higher than those of the group without pain, and that there were statistically significant differences in the case of questions 1, 6, and 7 . The questions that had higher averages were "Bending or twisting your back in an awkward way," "Continuing to work when injured or hurt," "Working in the same posture for long periods," and "Working in an inadequate environment" (Table 5). 
Table 3. Musculoskeletal symptoms, disability and demand for professional healthcare among the dentists, using Nordic Questionnaire [11], São Paulo, Brazil, 2014

\begin{tabular}{|c|c|c|c|c|}
\hline \multirow[b]{2}{*}{ Body area } & \multicolumn{4}{|c|}{$\begin{array}{l}\text { Respondents } \\
(\mathrm{N}=204) \\
{[\mathrm{n}(\%)]}\end{array}$} \\
\hline & $\begin{array}{l}\text { symptoms } \\
\text { in the last } 12 \text { months }\end{array}$ & $\begin{array}{l}\text { impediment to perform } \\
\text { normal activities because } \\
\text { of this problem over the } \\
\text { past year }\end{array}$ & $\begin{array}{l}\text { consultation with } \\
\text { a professional in the } \\
\text { area of health because } \\
\text { of this condition in the } \\
\text { past } 12 \text { months }\end{array}$ & $\begin{array}{l}\text { symptoms } \\
\text { in the last } 7 \text { days }\end{array}$ \\
\hline Neck & $113(55.4)$ & $32(15.7)$ & $53(26.0)$ & 37 (18.1) \\
\hline Shoulder & $106(52.0)$ & $26(12.7)$ & $45(22.1)$ & 40 (19.6) \\
\hline Upper back & $103(50.5)$ & $28(13.7)$ & $35(17.2)$ & 35 (17.2) \\
\hline Elbow & $32(15.7)$ & $10(4.9)$ & $17(8.3)$ & $10(4.9)$ \\
\hline Wrist/hand & $94(46.1)$ & $15(7.4)$ & $28(13.7)$ & $17(8.3)$ \\
\hline Lower back & 99 (48.5) & $32(15.7)$ & $47(23.0)$ & $42(20.6)$ \\
\hline Hip/thigh & $31(15.2)$ & $10(4.9)$ & $14(6.9)$ & $9(4.4)$ \\
\hline Knee & $45(22.1)$ & $12(5.9)$ & $20(9.8)$ & $10(4.9)$ \\
\hline Ankle/foot & $32(15.7)$ & $11(5.4)$ & $18(8.8)$ & $7(3.4)$ \\
\hline
\end{tabular}

Table 4. Association between the presence of pain and perception of risk factors for musculoskeletal disorders of the dentists, São Paulo, Brazil, 2014

\begin{tabular}{|c|c|c|c|}
\hline \multirow[t]{2}{*}{ Perception of risk factors } & \multicolumn{2}{|c|}{$\begin{array}{l}\text { Respondents } \\
(\mathrm{N}=204) \\
{[\mathrm{n}(\%)]}\end{array}$} & \multirow[t]{2}{*}{$\mathrm{p}$} \\
\hline & with pain & without pain & \\
\hline No problem & $14(8.4)$ & $10(26.3)$ & 0.018 \\
\hline Minimum to moderate problem & $134(80.7)$ & $25(65.8)$ & \\
\hline Severe problem & $18(10.8)$ & $3(7.9)$ & \\
\hline Total & $166(100.0)$ & $38(100.0)$ & - \\
\hline
\end{tabular}

Table 5. Perception of risk factors for musculoskeletal disorders and presence of pain in the dentists, using Work-related Questionnaire [13], São Paulo, Brazil, 2014

\begin{tabular}{|c|c|c|c|}
\hline \multirow[t]{2}{*}{ Work-related activity / Job factor } & \multicolumn{2}{|c|}{$\begin{array}{c}\text { Assesment by respondents } \\
(\mathrm{M} \pm \mathrm{SD}) \\
{[\mathrm{pts}]^{*}}\end{array}$} & \multirow[t]{2}{*}{$\mathrm{p}$} \\
\hline & with pain & without pain & \\
\hline "1. Performing the same task over and over" & $5.19 \pm 3.48$ & $4.03 \pm 3.64$ & 0.046 \\
\hline $\begin{array}{l}\text { "2. Working very fast for short periods (lifting, grasping, pulling, } \\
\text { etc.)" }\end{array}$ & $4.09 \pm 3.48$ & $3.63 \pm 3.63$ & 0.432 \\
\hline
\end{tabular}


Table 5. Perception of risk factors for musculoskeletal disorders and presence of pain among the dentists, using Work-related Questionnaire [13], São Paulo, Brazil, 2014 - cont.

\begin{tabular}{|c|c|c|c|}
\hline \multirow[t]{2}{*}{ Work-related activity / Job factor } & \multicolumn{2}{|c|}{$\begin{array}{c}\text { Assesment by respondents } \\
(\mathrm{M} \pm \mathrm{SD}) \\
{[\mathrm{pts}]^{*}}\end{array}$} & \multirow[t]{2}{*}{$\mathrm{p}$} \\
\hline & with pain & without pain & \\
\hline "3. Having to handle or grasp small objects" & $3.04 \pm 3.42$ & $2.34 \pm 3.31$ & 0.199 \\
\hline "4. Insufficient breaks or pauses during the work day" & $3.91 \pm 3.48$ & $3.39 \pm 3.11$ & 0.424 \\
\hline "5. Working in awkward or cramped positions" & $6.27 \pm 3.23$ & $5.11 \pm 3.99$ & 0.140 \\
\hline " 6 . Working in the same position for long periods" & $6.72 \pm 3.08$ & $5.13 \pm 3.91$ & 0.032 \\
\hline "7. Bending or twisting your back in an awkward way" & $7.13 \pm 4.84$ & $5.37 \pm 3.70$ & 0.022 \\
\hline "8. Working near or at your physical limits" & $5.77 \pm 3.44$ & $4.84 \pm 3.96$ & 0.205 \\
\hline "9. Reaching or working over your head or away from your body" & $4.71 \pm 3.74$ & $3.92 \pm 3.79$ & 0.236 \\
\hline "10. Hot, cold, humid, wet conditions" & $4.59 \pm 3.89$ & $5.05 \pm 4.33$ & 0.548 \\
\hline "11. Continuing to work when injured or hurt" & $4.30 \pm 3.61$ & $3.45 \pm 3.70$ & 0.193 \\
\hline "12. Carrying, lifting, or moving heavy materials or equipment" & $4.40 \pm 3.79$ & $4.55 \pm 4.14$ & 0.926 \\
\hline "13. Work scheduling (overtime, irregular shifts, length of workday)" & $6.92 \pm 3.21$ & $5.53 \pm 4.34$ & 0.193 \\
\hline "14. Using tools (design, weight, vibration, etc.)" & $3.23 \pm 3.41$ & $2.97 \pm 3.39$ & 0.650 \\
\hline "15. Training on how to do the job" & $3.02 \pm 3.53$ & $4.03 \pm 3.97$ & 0.168 \\
\hline
\end{tabular}

* Scale from 0 to $10(0$ = nothing, $10=$ a lot $)$.

$\mathrm{M}$ - mean; SD - standard deviation.

Table 6. Pain disability and pain intensity characteristics of the dentists, using the Pain Disability Questionnaire (PDQ) [15] and Numeric Pain Scale [17], São Paulo, Brazil, 2014

\begin{tabular}{lcc}
\hline & Variable & \multicolumn{2}{c}{$\begin{array}{c}\text { Respondents } \\
\text { (N=166) }\end{array}$} \\
\cline { 2 - 3 } & $\mathrm{n}$ & $\%$ \\
\hline Pain Disability Questionnaire (PDQ)* total & & \\
no disability & 40 & 24.1 \\
moderate disability & 126 & 75.9 \\
Numeric Pain Scale & & \\
none & 33 & 19.9 \\
minimum & 44 & 26.5 \\
moderate & 79 & 47.6 \\
severe & 10 & 6.0 \\
\hline
\end{tabular}

* The respondents didn't rate the scores for severe disability and an extreme disability.

Among the patients who reported presence of pain, we evaluated intensity of pain and disability created by it. Seventy-five point nine $\%$ of the dentists reported a "moderate" disability for work caused by pain. The average score in the Numeric Pain Scale was also categorized as moderate in $47.6 \%$ of the participants (Table 6). 
There was also a statistically significant correlation ( $p<0.001$ ) between the Pain Scale with PDQ. The correlations of the Pain Scale with the PDQ categories (functional condition (0.686), psychosocial component (0.638) and PDQ total (0.697) were strong and positive, i.e., as the Pain Scale went up, the PDQ went up as well.

\section{DISCUSSION}

São Paulo is a state situated in the south east of Brazil. It has high population density with the largest concentration of dentists in Brazil. The northeastern health region encompasses 40 municipalities in the region, with around 346 dentists who work in the dental clinics of health care units, emergency care units and dental specialists centers. Two hundred and four of those dentists participated in this study. They were hired to work $20 \mathrm{~h}$ per week or $40 \mathrm{~h}$ per week during 5 days to treat on average 8-10 patients per day. Dental filling and periodontal treatment were the most common dental procedures and they included: pediatric, oral surgery, endodontics and prosthodontics procedures. In general each dentist worked with a dental assistant.

Those dentists were exposed to numerous important risk factors for the development of occupational diseases as seen in the results of this study. Due to the high competitiveness of the job market, to improve their income they often performed multiple shifts at private and public clinics. The high prevalence of musculoskeletal disorders found in other studies may be also explained by exposure to awkward postures during the visits, management of vibrating tools, excessive working hours, often without breaks, and the precise movements performed [18-20]. Our study found similar results, probably because the dentists who participated in it worked in both the public and private service, with workload of more than $8 \mathrm{~h}$, without breaks between the sessions.

Even with the average of 21 years of clinical practice, professionals have 2 employment relationships that exert an intense workload. Organization of work in dentistry has changed along with the changes in the labor market in Brazil, resulting in increased workdays, shift work and the number of employment relationships. Moreover, the absence of breaks and costs of productivity became routine in the life of dentists, which together may influence their health [21].

Most of the dentists in this study were women, and neck and shoulder pain was significantly higher among the female dentists than males like it was in the Swedish study where female dentists had shown higher prevalence of symptoms during the past 12 months from the neck, shoulders, and hands/wrists [22]. Research shows that this gender has more chances to develop musculoskeletal disorders, because they experience a double workday in their day-to-day life, especially when living with a partner and children.

They are also responsible for household chores with less time for leisure activities and necessary rest, and, therefore, suffer from the effects caused by occupational tasks more than men do [23,24]. Another important factor is body mass index. Studies [23,25] have found that participants with high BMI (indicative of obesity) had more than twice higher the odds for MSDs - obesity aggravates pain at most sites of the body through increased mechanical strain and progression of joint damage in workers with arthritis.

Several studies performed in other countries bring forth evidence of the high prevalence of musculoskeletal disorders in the neck, shoulder and spine areas, as was found in the participants of this research. Among Polish dentists, $60.1 \%$ encountered prevalence of pain in the lumbar region, $56.3 \%$ in the neck, and $44 \%$ in the wrists/hands [26]. In a similar study with dental professionals in Denmark, pain in the lumbar region was also the most frequently reported type, being prevalent in 2/3 of the sample [27]. Alexandre et al. [28] have found that in Brazilian dentists the most affected area was the neck (57.5\%), while the prevalence in the lumbar region was relatively low (21.1\%). 
Awareness of the presence of risk factors at work among the participants of our study was similar to that in a study performed among dental hygiene technicians [29], where the factors considered as the most problematic ones were those related to a repetitive activity, static position for extended periods of time and flexing/bending of the spine. The dentists with the presence of pain had higher awareness of the presence of risk factors than those who did not report pain, and this shows that the fact that they have already experienced consequences of the symptoms arising from musculoskeletal disorders, makes these professionals more attentive to the problems related to the practice of their profession.

Correlation between scores of the PDQ and the Numeric Pain Scale was significant and of strong magnitude $(\mathrm{r}=0.697)$. While validating the PDQ, a previous study has correlated disability with intensity of pain, using an analog pain scale, and it has found a moderate relationship ( $\mathrm{r}=0.44$ ), which suggests that there is a relationship between intensity of pain and the perception of disability [19]. Another study has found a strong correlation between intensity of pain and pain disabilities in patients with lumbar pain $(r=0.62)$ [30]. Literature published in scientific journals has shown that to study the relationship between intensity of pain and disabilities one must consider a series of variables, inter alia: frequency and location of pain, presence of depression, beliefs about pain [31]. Several studies have found that psychological and psychosocial factors may also increase the risk of musculoskeletal disorders [32,33]. The risk factors which were most frequently mentioned by researchers were: work dissatisfaction, low control over work, stress, mental suffering and monotonous work $[34,35]$.

Pain disabilities are a complex phenomenon, with a negative impact on the quality of life of professionals. Inability to perform work and domestic activities is evidence that the symptoms arising from musculoskeletal disorders interfere to an important extent with the life of such workers. The results of this research alert us to the risk factors present in the workplaces of dentists in Brazil, and may be applied to dental professionals in other countries. This fact should be considered with care by the agencies responsible for the health of workers in Brazil, such as the Ministries of Health and Labor and Work at the federal level, and the state and municipal departments in both sectors, just as by the agencies responsible in other countries, since the presence of pain arising from the daily practice of dentistry may cause irreversible damage in dentists' lives.

\section{CONCLUSIONS}

In this study we found that the dentists presented high prevalence of musculoskeletal disorders in the regions of neck, shoulders, spine and wrists/hands. The dentists with presence of pain had higher awareness of the presence of risk factors than those who did not report pain. This shows that the fact that they have already experienced consequences of the symptoms arising from musculoskeletal disorders, makes these professionals more attentive to the problems related to the practice of their profession. Disability created by pain in the symptomatic participants was moderate and was associated with the intensity of pain.

\section{REFERENCES}

1. Mattioli S, Baldasseroni A, Bovenzi M, Curti S, Cooke RMT, Campo G, et al. Risk factors for operated carpal tunnel syndrome: A multicenter population-based case-control study. BMC Public Health. 2009;9:343, https://doi.org/10.1186/14712458-9-343.

2. Karwowski W, Marras WS. Occupational ergonomics: Principles of work design. Florida: CRC Press; 2003.

3. Leggat PA, Kedjarune U, Smith DR. Occupational health problems in modern dentistry. Ind Health. 2007 Oct;45(5): 611-21, https://doi.org/10.2486/indhealth.45.611.

4. Morse T, Bruneau H, Dussetschleger J. Musculoskeletal disorders of the neck and shoulder in the dental professions. Work. 2010;35(4):419-29, https://doi.org/10.3233/WOR-20 10-0979. 
5. Lin TH, Liu YC, Hsieh TY, Hsiao FY, Lai YC, Chang CS. Prevalence of and risk factors for musculoskeletal complaints among Taiwanese dentists. J Dent Sci. 2012;7:65-71, https://doi.org/10.1016/j.jds.2012.01.009.

6. Hayes M, Cockrell D, Smith DR. A systematic review of musculoskeletal disorders among dental professionals. Int J Dent Hyg. 2009;7(3):159-65, https://doi.org/10.1111/ j.1601-5037.2009.00395.x.

7. Morse T, Bruneau H, Michalak-Turcotte C, Sanders M, Warren N, Dussetschleger J, et al. Musculoskeletal disorders of the neck and shoulder in dental hygienists and dental hygiene students. J Dent Hyg. 2007;81(1):10.

8. Ylipaa V, Arnetz BB, Benko SS, Ryden H. Physical and psychosocial work environments among Swedish dental hygienists: Risk indicators for musculoskeletal complaints. Swed Dent J. 1997;21(3):111-20.

9. Crawford L, Gutierrez G, Harber P. Work environment and occupational health of dental hygienists: A qualitative assessment. J Occup Environ Med. 2005;47(6):623-32, https:// doi.org/10.1097/01.jom.0000165744.47044.2b.

10. Lillefjell M, Jakobsen K. Sense of coherence as a predictor of work reentry following multidisciplinary rehabilitation for individuals with chronic musculoskeletal. J Occup Health Psychol. 2007;12(3):222-31, https://doi.org/10.1037/1076-8998.12.3.222.

11. Kuorinka I, Jonsson B, Kilbom A, Vinterberg H, Biering-Sorensen F, Andersson G, et al. Standardised Nordic questionnaires for the analysis of musculoskeletal symptoms. Appl Ergon. 1987;18:233-7, https://doi.org/10.1016/0003-6870(87)90010-X.

12. Barros ENC, Alexandre NMC. Cross-cultural adaptation of the Nordic musculoskeletal questionnaire. Int Nurs Rev. 2003;50(2):101-8, https://doi.org/10.1046/j.1466-7657.2003. 00188.x.

13. Rosecrance JC, Cook TM, Zimmermann CL. Work-related musculoskeletal disorders among construction workers in the pipe trades. Work. 1996;7:13-20, https://doi.org/10.3233/ WOR-1996-7103.

14. Coluci MZO, Alexandre NMC. [Cross-cultural adaptation of an instrument to measure work-related activities that may contribute to osteomuscular symptoms]. Acta Paul Enferm. 2009;22(2):149-54, https://doi.org/10.1590/S010321002009000200006. Portuguese.

15. Anagnostis C, Gatchel RJ, Mayer TG. The Pain Disability Questionnaire: A new psychometrically sound measure for chronic musculoskeletal disorders. Spine. 2004;29(20):2290302, https://doi.org/10.1097/01.brs.0000142221.88111.0f.

16. Giordano PCM, Alexandre NMC. [Cultural adaptation and validation of the instrument: The Pain Disability Questionnaire]. Campinas (SP): State University of Campinas; 2009. Portuguese.

17. Gallasch $\mathrm{CH}$, Alexandre NMC. The measurement of musculoskeletal pain intensity: A comparison of four methods. Rev Gaucha Enferm. 2007;28(2):260-5.

18. Dantas FFO, de Lima KC. The relationship between physical load and musculoskeletal complaints among Brazilian dentists. Appl Ergon. 2015;47:93-8, http://doi.org/10.1016/ j.apergo.2014.09.003.

19. Santos Filho SB, Barreto SM. [Occupational activity and prevalence of upper-limb and back pain among dentists in Belo Horizonte, Minas Gerais State, Brazil: A contribution to the debate on work-related musculoskeletal disorders]. Cad Saude Publica. 2001;17(1):181-93, https://doi. org/10.1590/S0102-311X2001000100019. Portuguese.

20. Garbin A, Garbin C, Moimaz S, Baldan R, Zina L. Dental practice and musculoskeletal disorders association: A look at the evidence. Arch Environ Occup Health. 2011;66:26-33, https://doi.org/10.1080/19338244.2010.506493.

21. Garbin CAS, Saliba O, Gonçalves PE. [Burnout syndrome: The stress of the modern dentist]. Rev Assoc Paul Cir Dent. 2006;60(2):131-3. Portuguese.

22. Akesson I, Schutz A, Horstmann V, Moritz V. Musculoskeletal symptoms among dental personnel - Lack of association with mercury and selenium status, overweight and smoking. Swed Dent J. 2000;24:23-38.

23. Rafie F, Zamani Jam A, Shahravan A, Raoof M, Eskandarizadeh A. Prevalence of upper extremity musculoskeletal disorders in dentists: Symptoms and risk factors. 
J Environ Public Health. 2015;2015:517346, https://doi. org/10.1155/2015/517346.

24. Zoidaki A, Riza E, Kastania A, Papadimitriou E, Linos A. Musculoskeletal disorders among dentists in the Greater Athens area, Greece: Risk factors and correlations. J Public Health. 2013;21(2):163-73, https://doi.org/10.1007/s10389012-0534-7.

25. Werner RA, Albers JW, Franzblau A, Armstrong TJ. The relationship between body mass index and the diagnosis of carpal tunnel syndrome. Muscle Nerve. 1994;17(6):632-6, https://doi.org/10.1002/mus.880170610.

26. Szymańska J. Disorders of the musculoskeletal system among dentists from the aspect of ergonomics and prophylaxis. Ann Agric Environ Med. 2002;9:169-73.

27. Finsen L, Christensen H, Bakke M. Musculoskeletal disorders among dentists and variation in dental work. Appl Ergon. 1998;29:119-25, https://doi.org/10.1016/S0003-6870(97)00017-3.

28. Alexandre P, da Silva I, de Souza L, Camara V, Palacios M, Meyer A. Musculoskeletal disorders among Brazilian dentists. Arch Environ Occup Health. 2011;66:231-5, https:// doi.org/10.1080/19338244.2011.564571.

29. Anton D, Rosecrance J, Merlino L, Cook T. Prevalence of musculoskeletal symptoms and carpal tunnel syndrome among dental hygienists. Am J Ind Med. 2002;42:248-57, https://doi.org/10.1002/ajim.10110.

30. Grönblad M, Hupli M, Wennerstran P, Järvinen E, Lukinmaa A, Kouri JP, et al. Intercorrelation and test-retest reliability of the Pain Disability Index (PDI) and the Oswestry Disability Questionnaire (ODQ) and their correlation with pain intensity in low back pain patients. Clin J Pain. 1993;9:189-95, https://doi.org/10.1097/00002508-19930900000006.

31. Geisser EM, Robinson ME, Miller QL, Geertzen JHB, Dijkstra PU. Psychosocial factors and functional capacity evaluation among persons with chronic pain. J Occup Rehabil. 2003;4(13):259-76, https://doi.org/10.1023/A:1026272721813.

32. De Ruijter RAG, Stegenga B, Schaub RMH, Reneman MF, Middel B. Determinants of physical and mental health complaints in dentists: A systematic review. Community Dent Oral Epidemiol. 2015;43:86-96, https://doi.org/10.1111/cdoe.12122.

33. Hoogendoorn WE, van Poppel MNM, Bongers PM, Koes BW, Bouter LM. Systematic review of psychosocial factors at work and private life as risk factors for back pain. Spine. 2000;25:2115-25, https://doi.org/10.1097/00007632200008150-00017.

34. Da Costa BR, Vieira ER. Risk factors for work-related musculoskeletal disorders: A systematic review of recent longitudinal studies. Am J Ind Med. 2010;53(3):285-323, http://doi. org/10.1002/ajim.20750.

35. Violante FS, Fiori M, Fiorentini C, Risi A, Garagnani G, Bonfiglioli R, et al. Associations of psychosocial and individual factors with 3 different categories of back disorder among nursing staff. J Occup Health. 2004;46:100-8, https:// doi.org/10.1539/joh.46.100.

This work is available in Open Access model and licensed under a Creative Commons Attribution-NonCommercial 3.0 Poland License - http://creativecommons.org/ licenses/by-nc/3.0/pl/deed.en. 